\begin{tabular}{|c|l|}
\hline Title & Zoosporicidal activities of anacardic acids against A phanomyces cochlioides. \\
\hline Author(s) & Begum, Parvin; Hashidoko, Y asuy uki; Islam, Md Tofazzal; Ogawa, Y uko; Tahara, Satoshi \\
\hline Citation & Zeitschrift für Naturforschung. C, Journal of biosciences, 57(9-10), 874-882 \\
\hline Issue Date & 2002-09 \\
\hline Doc URL & http:/hdl.handle.net/2115/45252 \\
\hline Type & article \\
\hline File Information & Parvin.pdf \\
\hline
\end{tabular}

Instructions for use 


\section{Zoosporicidal Activities of Anacardic Acids against Aphanomyces cochlioides}

Parvin Begum, Yasuyuki Hashidoko*, Md. Tofazzal Islam, Yuko Ogawa and Satoshi Tahara

Division of Applied Bioscience, Graduate School of Agriculture, Hokkaido University, Kita-Ku, Kita-9, Nishi-9, Sapporo 060-8589, Japan. Fax: +81-11-706-41 82 E-mail: yasu-h@abs.agr.hokudai.ac.jp

* Author for correspondence and reprint requests

Z. Naturforsch. 57 c, 874-882 (2002); received May 21/June 22, 2002

Anacardic Acids, Ginkgo biloba, Zoospore Lysis

The EtOAc soluble constituents of the unripe fruits of Ginkgo biloba showed motility inhibition followed by lysis of zoospores of the phytopathogenic Aphanomyces cochlioides. We purified 22:1- $\omega^{7}$-anacardic acid (1), 24:1- $\omega^{9}$-anacardic acid (2) and 22:0-anacardic acid (3), together with other related compounds, 21:1- $\omega^{7}$-cardol (4) and 21:1- $\omega^{7}$-cardanol (5) from the crude extracts of Ginkgo fruits. Amongst them, compound $\mathbf{1}$ was a major active agent in quality and quantity, and showed potent motility inhibition ( $98 \%$ in $30 \mathrm{~min}$ ) followed by lysis $\left(55 \%\right.$ in $3 \mathrm{~h}$ ) of the zoospores at $1 \times 10^{-7} \mathrm{M}$. The $2-O$-methyl derivative $(\mathbf{1}-\mathbf{c})$ of $\mathbf{1}$ displayed antibacterial activity against Bacillus subtilis, but practically inactive to Escherichia coli. A brief study on structure-activity relationships revealed that a carboxyl group on the aromatic ring and an unsaturated side chain in the anacardic acid derivative are important for strong motility inhibitory and lytic activities against the zoospore.

\section{Introduction}

Ginkgo biloba L. is one of the most important medicinal plants that received a considerable interest (Jaggy and Koch, 1997; Wang et al., 1998; Briskin, 2000). It is a valuable source of several groups of natural products such as phenolic lipids (Zarnowska et al., 2000), terpenoids (ginkgolides and bilobalide), and flavonoids (Ginkgo-flavone glycosides) (Briskin, 2000). Previous works on phenolic lipids of G. biloba revealed that it contains anacardic acids, cardanols, and cardols with alk(en)yl side chains differing in the chain length and the unsaturation patterns (Lepoittevin et al., 1989; Himejima and Kubo, 1991; Irie et al., 1996). In particular, anacardic acids are known to inhibit enzymes such as prostaglandin synthase (Grazzini et al., 1991), tyrosinase (Kubo et al., 1994) and lipoxygenase (Shobha et al., 1994), and also known to exhibit antitumor (Itokawa et al., 1987) and antimicrobial (Himejima and Kubo, 1991) activities.

During the survey of physiologically active secondary metabolites toward zoospores of Aphanomyces cochlioides, we observed that the EtOAc soluble extracts of unripe Ginkgo fruits induced potent motility inhibition followed by lysis of the zoospores. This unusual phenomenon prompted us to investigate the active constituents in the extract.
This paper describes the isolation of $22: 1-\omega^{7}$-anacardic acid (1) as a major active compound and biological activities of $\mathbf{1}$ and related compounds against the fungal zoospores and two bacteria.

\section{Materials and Methods}

\section{General}

Merck silica gel $60 \mathrm{~F}_{254}$ pre-coated on glass plates was used for analytical and preparative TLC. Column chromatography was conducted using silica gel 60 (spherical, Merck 100-200 mesh). High performance liquid chromatography (HPLC) was carried out by a Hitachi D-7500 equipped with a reversed phase column Prep-ODS (RP-C18, $20 \times 250 \mathrm{~mm}$, GL Sciences Inc., Tokyo) using aq. $\mathrm{MeOH}$ as eluting solvent with a flow rate at $10 \mathrm{ml} / \mathrm{min}$, otherwise, specially mentioned in the text. Chemical substances were detected and monitored by a UV detector at wavelength of $254 \mathrm{~nm}$. ${ }^{1} \mathrm{H}$ NMR spectra were recorded on a JEOL JNMEX270 FT-NMR spectrometer at $270 \mathrm{MHz}$ using TMS as an internal standard in deuterated chloroform. FD-MS and EI-MS spectra were acquired on a JEOL JMS-SX102A and a JEOL DX 500 spectrometers, respectively. Electron microscopic 
observation was done by a scanning electron microscope (JEOL JSM-6301F).

\section{Plant material and chemicals}

The unripe Ginkgo (G. biloba) fruits were collected in August 2000 at the campus of Hokkaido University, Sapporo, Japan. The whole unripe Ginkgo fruits $(15 \mathrm{~kg})$ were extracted with $\mathrm{MeOH}$ (10 l) and the $\mathrm{MeOH}$ extract was concentrated in vacuo to remove the solvent. The resulting aqueous solution was diluted with deionized water to 41 and extracted successively with $n$-hexane (4 1) and then EtOAc (4 1). The EtOAc solubles ( $c a$. $70 \mathrm{~g}$ ) were chromatographed on a silica gel (900 g) column and the constituents were eluted with a mixture of $n$-hexane and EtOAc $(15: 1 \mathrm{v} / \mathrm{v})$ to yield $40 \mathrm{~g}$ of an anacardic acid-mixture (1 $\mathbf{~ m})$. Fluazinam (6) was purchased from Wako Pure Chemical Ind. Ltd., Osaka.

\section{Derivatization of a mixture of anacardic acids (1 $\mathbf{~ m )}$}

A part of the anacardic acid mixture $(\mathbf{1} \mathbf{~ m}, 1.5 \mathrm{~g})$ was refluxed in conc. $\mathrm{H}_{2} \mathrm{SO}_{4}-\mathrm{MeOH}(1: 20 \mathrm{v} / \mathrm{v})$ followed by silica gel column chromatography to yield a mixture of methyl esters (1 $\mathbf{~ m - a}, 975 \mathrm{mg}$ ) and a slowly eluting non-derivatizable constituent (99 $\mathrm{mg}$ ). Both carboxyl and phenolic $\mathrm{OH}$ groups of $\mathbf{1} \mathbf{~ m}$ were methylated by treating $\mathbf{1} \mathbf{~ m}$ with $\mathrm{Me}_{2} \mathrm{SO}_{4}$ and $\mathrm{K}_{2} \mathrm{CO}_{3}$ in acetone to give $\mathbf{1} \mathbf{~ m}-\mathbf{b}$. The resulting derivative $\mathbf{1} \mathbf{~ m}-\mathbf{b}$ was refluxed in a mixture of MeOH-aq. $2 \mathrm{M} \mathrm{NaOH}(1: 1)$ for $3 \mathrm{~h}$ to give 2-O-methylanacardic acids (1 $\mathbf{~ m - c )}$. Reduction of $\mathbf{1} \mathbf{~ m - a}$ and $\mathbf{1} \mathbf{~ m}$-b with $\mathrm{LiAlH}_{4}$ in EtOH/THF resulted in yielding compounds $\mathbf{1}$ m-d and $\mathbf{1}$ m-e. Pyrolytic decarboxylation of $\mathbf{1} \mathbf{~ m}$ was done at $170{ }^{\circ} \mathrm{C}$ for $3 \mathrm{~h}$, using $2 \%$ acetone/glycerol mixture as the matrix in sealed glass tubes. After the reaction process, the reaction mixture was diluted with water and then extracted with EtOAc to give decarboxylated product $\mathbf{1} \mathbf{m}-\mathbf{f}$ (a mixture of cardanol homologues). Methylation of $\mathbf{1} \mathbf{~ m - f}$ with $\mathrm{Me}_{2} \mathrm{SO}_{4}$ and $\mathrm{K}_{2} \mathrm{CO}_{3}$ in acetone yielded compound $\mathbf{1} \mathbf{~ m - g}$ ( = 2-O-methyl-1 m-f).

Isolation of anacardic acid homologues (1-3), 21:1- $\omega^{7}$-cardol (4) and 21:1- $\omega^{7}$-cardanol (5)

A mixture of methyl anacardates $(\mathbf{1} \mathbf{~ m - a})$ was applied to medium-pressure column chromatogra- phy using an ODS column eluted with $3 \% \mathrm{H}_{2} \mathrm{O} /$ $\mathrm{MeOH}$ to give two major peaks (fr. 1 and fr. 2, 478 and $360 \mathrm{mg}$, respectively). The major component in fr. 1 was further purified by HPLC (Prep-ODS column, $1 \% \mathrm{H}_{2} \mathrm{O} / \mathrm{MeOH}$, flow rate $5 \mathrm{ml} / \mathrm{min},{ }^{\mathrm{t}} R-$ $66.6 \mathrm{~min}$ ) to yield $281 \mathrm{mg}$ of $\mathbf{1 a}$. From the latter fraction, two major peaks were separable by HPLC (Prep-ODS column, 3\% $\mathrm{H}_{2} \mathrm{O} / \mathrm{MeOH}$ ) to give $280 \mathrm{mg}$ of crude $\mathbf{2 a}$ and $60 \mathrm{mg}$ of crude $\mathbf{3 a}$ as an oil, respectively. The compounds $2 \mathbf{a}$ and $\mathbf{3 a}$ were purified from each HPLC fraction by repeated HPLC (100\% $\mathrm{MeOH}$, flow rate $5 \mathrm{ml} / \mathrm{min})$ as a colorless oil (180 and $24 \mathrm{mg}$, respectively).

Methylated products (1a, 2a and 3a) thus purified were separately hydrolyzed in $\mathrm{MeOH}$-aq. $2 \mathrm{M} \mathrm{KOH} \mathrm{(1:1)} \mathrm{and} \mathrm{the} \mathrm{resulting} \mathrm{products} \mathrm{purified}$ by preparative TLC ( $n$-hexane-EtOAc-HCOOH, $14: 2: 1 \mathrm{v} / \mathrm{v} / \mathrm{v})$ to yield $\mathbf{1}, \mathbf{2}$ and $\mathbf{3}$, respectively in good yields. The derivatization and transformation reactions were similarly applied to highly purified $\mathbf{1}$ to prepare 1-b and 1-c. Pure $\mathbf{1}$ was hydrogenated with $\mathrm{H}_{2}$ /palladium carbon to yield a quantitative amount of $\mathbf{3}$.

21:1- $\omega^{7}$-Cardol (4) containing fraction $(66 \mathrm{mg})$ eluted from the first silica gel column followed after the anacardic acid mixture was purified by preparative TLC in $\mathrm{CHCl}_{3}$-EtOAc- $\mathrm{HCOOH}$ (60:10:3, v/v/v, $\left.R_{\mathrm{f}} 0.27,35 \mathrm{mg}\right) .21: 1-\omega^{7}$-Cardanol (5) found the unchanged constituent (99 $\mathrm{mg}$ ) in the methylation reaction mixture of $1.5 \mathrm{~g}$ of $\mathbf{1} \mathbf{~ m}$ was separated by preparative TLC $\left(R_{\mathrm{f}} 0.65\right.$ in $\left.\mathrm{CHCl}_{3}-\mathrm{EtOAc}-\mathrm{HCOOH}=60: 10: 3\right)$, and finally purified by HPLC (Prep-ODS column, 3\% $\mathrm{H}_{2} \mathrm{O} /$ $\mathrm{MeOH},{ }^{\mathrm{t}} R-53.3 \mathrm{~min}$ ) to give $40 \mathrm{mg}$ of a colorless syrup.

Culture of Aphanomyces cochlioides, preparation of zoospore suspensions, and bioassay

Culture of A. cochlioides AC-5 and production of its zoospores were done as described previously (Horio et al., 1992). For zoospore assay, we used both particle method (Tahara et al., 1999) and homogeneous solution method (Shimai et al., 2002). In the former method, particles of Chromosorb W AW (60/80 mesh) were coated with a test compound solved in EtOAc at a set concentration, and some of the particles were then carefully dropped into $2 \mathrm{ml}$ of a zoosopore suspension (original zoospore suspension, ca. $2 \times 10^{5} / \mathrm{ml}$, was 
diluted 2-3 times before each experiment) in a small petri dish ( $3 \mathrm{~cm}$ i.d.). The behavior of zoospores around the particle was observed for several hours after addition of the particles under a microscope (x 53). As a control, particles treated with solvent alone were used. The latter method mainly employed in the present study was $100-$ 1000 fold sensitive in comparison with the particle method. The test compounds were initially dissolved in DMSO and then diluted with water. To each well of a 24-hole petri dish (16 mm i.d.), $450 \mu \mathrm{l}$ of the zoospore suspension and $50 \mu \mathrm{l}$ of the test compound solution were added and gently stirred. The final concentration of DMSO was adjusted to $0.1 \%$. The original zoospore suspension (ca. $2 \times 10^{5} / \mathrm{ml}$ ) was initially diluted (usually $2-3$ times) with appropriate amount of water to adjust the zoospore density which gives 30-60 zoospores in each microscopic field when all zoospores are halted swimming and settling down on the bottom of the petri dish (16 mm i.d.). The numbers of zoospores in the test solution were counted as follows: once mechanically stimulated by a vortex for $30 \mathrm{sec}$, all zoospores in the suspension halted swimming instantly and sunk to the bottom of the petri dish within $5 \mathrm{~min}$, which makes possible to count the numbers of zoospores under a microscope (x 53).

Evaluation of motility inhibitory and lytic activities of the test compounds

Only preliminary evaluation of lytic activity against the zoospores of the anacardic acid mixture $(\mathbf{1} \mathbf{~ m})$ and its derivatives $(\mathbf{1} \mathbf{~ m - a}-\mathbf{1} \mathbf{~ m}-\mathbf{b})$ was carried out by particle method (see Table I) and the injured/burst spores were counted. Other experiments using purified samples were conducted by homogeneous solution method (Tables II and III). When zoospores were exposed to $1 \times 10^{-5} \mathrm{M}$ of fluazinam (6), nearly $100 \%$ zoospores were instantly halted and shown remarkable lytic activity. Therefore, compound $\mathbf{6}$ was used as the positive control in our quantitative bioassay to measure fungal zoospores halted-and-sunk and/or burst. Compound $\mathbf{1}$ also showed almost the equivalent halting activity to that of the reference fungicide (6). The numbers of halted-and-sunk spores effected by test compounds at $1 \times 10^{-6}-10^{-8} \mathrm{M}$ up to 5-30 min were recorded by a digital camera
(OLYMPUS Camedia C-3040 200M) and numbers of zoospores settling down on the bottom of each petri dish were counted to compare with that of vortex-stimulated zoospore suspension in each microscopic field. At 30, 60, 120, and 180 min after the treatment, uninjured spores on the bottom of each petri dish were counted in the same manner described above to evaluate the lytic activity of tested compounds. As a control solution for this bioassay was used $0.1 \%$ DMSO alone.

\section{Scanning electron microscopy}

22:1- $\omega^{7}$-Anacardic acid (1) was first dissolved in small quantities of DMSO and then diluted with distilled water. Appropriate amounts of sample suspension were directly added into the zoospore suspension taken on a SEMpore membrane to take final volume as $200 \mu \mathrm{l}$. The concentrations of $\mathbf{1}$ and DMSO in the zoospore suspension were $5 \times 10^{-5} \mathrm{M}$ and $0.1 \%$, respectively. After a set interval $(10,20$ and $60 \mathrm{~min})$ of treatments, the specimen was fixed with $2 \%$ buffered glutaraldehyde, and the rest of the procedures for scanning electron microscopy were carried out as described previously (Islam et al., 2001).

\section{Antimicrobial assay}

As test microbes, two bacteria (Bacillus subtilis AHU1036 (Laboratory of Applied Microbiology, Graduate School of Agriculture, Hokkaido University, Japan) and Escherichia coli IFO 3301 (Institute for Fermentation, Osaka)) and a fungus (Pythium vexans) isolated from soil by Dr. Kasuya (Yamaji et al., 2000) were used. The antimicrobial tests of major compounds by means of paper disc method were done on nutrient-broth agar and potato-dextrose agar media for the bacteria and for $P$. vexans, respectively. All of the tests were triplicated.

\section{Results and Discussion}

\section{Isolation and derivatization of anacardic acids}

The procedures for isolation of anacardic acids (1-3), cardol (4) and cardanol (5) from Ginkgo fruits and derivatization of the anacardic acids were described in the section of Materials and Methods. Chemical structures of all isolated com- 
<smiles>[R20]Oc1cccc([R20])c1C(=O)O</smiles>

1: $\mathrm{R}_{1}=\overbrace{}^{,} \mathrm{R}_{2}=\mathrm{R}_{3}=\left(22: 1 \omega^{7}\right.$-anacardic acid $)$

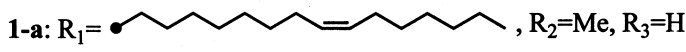

1-b: $\mathrm{R}_{1}=$, $\mathrm{R}_{2}=\mathrm{Me}, \mathrm{R}_{3}=\mathrm{Me}$

1-c: $\mathrm{R}_{1}=\overbrace{, \mathrm{R}_{2}=\mathrm{H}, \mathrm{R}_{3}=\mathrm{Me}}$

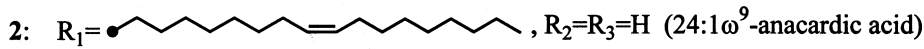

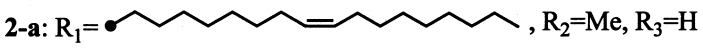

3: $\mathrm{R}_{1}=\mathrm{N}_{2}=\mathrm{R}_{3}=\mathrm{H}$ (22:0-anacardic acid)

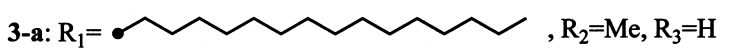

HO<smiles>[R]c1cccc(CCCCCCC/C=C/CCCCCC)c1</smiles>

4: $\mathrm{R}_{1}=\mathrm{OH}\left(21: 1 \omega^{7}\right.$-cardol $)$

5: $\mathrm{R}_{1}=\mathrm{H}\left(21: 1 \omega^{7}\right.$-cardanol)<smiles>[R]c1cccc(F)c1[R]</smiles>

$\mathrm{R}=\mathrm{a}$ mixture of 1, 2, 3-type side chains

1m: $\mathrm{R}_{1}=\mathrm{COOH}, \mathrm{R}_{2}=\mathrm{OH}$

1m-d: $\mathrm{R}_{1}=\mathrm{CH}_{2} \mathrm{OH}, \mathrm{R}_{2}=\mathrm{OH}$

1m-a: $\mathrm{R}_{1}=\mathrm{COOMe}, \mathrm{R}_{2}=\mathrm{OH}$

1m-e: $\mathrm{R}_{1}=\mathrm{CH}_{2} \mathrm{OH}, \mathrm{R}_{2}=\mathrm{OMe}$

1m-b: $\mathrm{R}_{1}=\mathrm{COOMe}, \mathrm{R}_{2}=\mathrm{OMe}$

1m-f: $\mathrm{R}_{1}=\mathrm{H}, \mathrm{R}_{2}=\mathrm{OH}$

1m-c: $\mathrm{R}_{1}=\mathrm{COOH}, \mathrm{R}_{2}=\mathrm{OMe}$

1m-g: $\mathrm{R}_{1}=\mathrm{H}, \mathrm{R}_{2}=\mathrm{OMe}$<smiles>O=[N+]([O-])c1cc(C(F)(F)F)c(Cl)c([N+](=O)[O-])c1Nc1ncc(C(F)(F)F)cc1Cl</smiles>

6: fluazinam
Fig. 1. Structures of anacardic acids and related compounds tested for their activities toward zoospores of A. cochlioides and some other microorganisms. pounds (1-5) were confirmed on the basis of their spectral data compared with the reported ones (Itokawa et al., 1987; Yamagiwa et al., 1987; Irie et al., 1996). Derivatization of an anacardic acid mixture (1 $\mathbf{~ m}$ ) was also described in Materials and Methods. The structures of the derivatives (1 $\mathbf{m - a}-\mathbf{1} \mathbf{m - f})$ from an anacardic acid mixture (1 $\mathbf{~ m})$ were spectroscopically confirmed.
Biological activities of anacardic acids and related compounds toward the Aphanomyces cochlioides zoospores

When Chromosorb W AW particles coated with 1000-ppm solution of EtOAc solubles of unripe Ginkgo fruits were subjected to a zoospore bioassay (particle method), the motility of zoospores around the particles was suddenly inhibited and followed by cell lysis. In homogeneous solution 
Table I. Lytic activity of a mixture of anacardic acids (1 $\mathbf{~ m}), 21: 1 \omega^{7}$-cardol (4), 21:1 $\omega^{7}$-cardanol (5) and derivatives of $\mathbf{1 ~ m}$ (structures, in Fig. 1) against Aphanomyces cochlioides zoospores tested by particle method*.

\begin{tabular}{lcccccccccc}
\hline Compound & $\mathbf{1 ~ m}$ & $\mathbf{1} \mathbf{~ m - a}$ & $\mathbf{1} \mathbf{m}-\mathbf{b}$ & $\mathbf{1} \mathbf{~ m - c}$ & $\mathbf{1} \mathbf{m}-\mathbf{d}$ & $\mathbf{1} \mathbf{m}-\mathbf{e}$ & $\mathbf{1 ~ m - f}$ & $\mathbf{1 ~ m - g}$ & $\mathbf{4}$ & $\mathbf{5}$ \\
& $27 \pm 0.6$ & - & - & $40 \pm 0.6$ & - & - & - & - & $6 \pm 0.9$ & - \\
\hline
\end{tabular}

* In this experiment, Chromosorb W AW particles were coated with each 1000-ppm solution and 3 particles were dropped into the petri dish $(3 \mathrm{~cm}$ i.d.) containing $2 \mathrm{ml}$ of a zoospore suspension. The lytic activity was observed around the particles under a microscope (x 53) after $3 \mathrm{~h}$. In this bioassay, the zoospore density was adjusted $c a .60$ per microscopic field and injured/burst zoospores around the particles were counted. Results are shown as an average of four microscopic fields \pm SE.

method (Shimai et al., 2002), the active EtOAc fraction exhibited lytic activity at a range of $0.1-$ 1 ppm (data not shown) toward A. cochlioides zoospores. After adding the sample solution into the zoospore suspension, cells quickly became immobile or moved in an unusual circular fashion for a few minutes and then halted. Initially the halted zoospores became round-shaped spores by losing their flagella and part of them were burst gradually.
Our preliminary bioassay by particle method revealed that in the crude anacardic acid mixture $(\mathbf{1 ~ m})$, chemically derivatized anacardates $(\mathbf{1} \mathbf{~ m - a}$ to $\mathbf{1} \mathbf{~ m - g}$ ), cardol (4) and cardanol (5), $1 \mathbf{m}$ and 2- $O$-methyl derivative (1 $\mathbf{~ m - c ) ~ h a d ~ s i g n i f i c a n t ~ l y s i s - ~}$ inducing activity against zoospores (Table I). 21: 1- $\omega^{7}$-Cardol (4), one of non-carboxylated Ginkgo metabolites, also showed similar, but weak activity. However, carboxyesters (1 $\mathbf{~ m - a}$ and $1 \mathbf{~ m - b})$, benzyl alcohol-type derivatives (1 $\mathbf{m}-\mathbf{d}$ and $\mathbf{1} \mathbf{m}-\mathbf{e})$, and

Table II. Motility inhibition of Aphanomyces cochlioides zoospores in the presence of anacardic acids (1, 2 and 3), cardol (4), 2-O-methyl-22:1 $\omega^{7}$-anacardic acid (1-c) and a reference compound fluazinam (6).

\begin{tabular}{|c|c|c|c|c|c|}
\hline \multirow[b]{2}{*}{$\begin{array}{l}\text { Tested } \\
\text { compound }\end{array}$} & \multirow[b]{2}{*}{$\begin{array}{c}\text { Concentration } \\
{[\mathrm{M}]}\end{array}$} & \multicolumn{4}{|c|}{ Observed motility inhibition activity* } \\
\hline & & $5 \mathrm{~min}$ & $10 \mathrm{~min}$ & $20 \mathrm{~min}$ & $30 \mathrm{~min}$ \\
\hline \multirow[t]{3}{*}{1} & $1 \times 10^{-6}$ & $51 \pm 2.5$ & $75 \pm 1.9$ & $98 \pm 3.3$ & $101 \pm 2.5$ \\
\hline & $1 \times 10^{-7}$ & $37 \pm 2.6$ & $60 \pm 6.3$ & $82 \pm 4.8$ & $98 \pm 2.2$ \\
\hline & $1 \times 10^{-8}$ & $22 \pm 2.5$ & $47 \pm 2.1$ & $66 \pm 3.4$ & $81 \pm 2.0$ \\
\hline \multirow[t]{3}{*}{2} & $1 \times 10^{-6}$ & $39 \pm 1.2$ & $55 \pm 2.6$ & $72 \pm 2.0$ & $99 \pm 1.6$ \\
\hline & $1 \times 10^{-7}$ & $24 \pm 1.2$ & $36 \pm 3.1$ & $58 \pm 3.3$ & $83 \pm 3.9$ \\
\hline & $1 \times 10^{-8}$ & $9 \pm 1.2$ & $21 \pm 1.9$ & $40 \pm 5.4$ & $69 \pm 2.0$ \\
\hline \multirow[t]{3}{*}{3} & $1 \times 10^{-6}$ & $27 \pm 3.2$ & $36 \pm 5.0$ & $54 \pm 4.8$ & $99 \pm 2.0$ \\
\hline & $1 \times 10^{-7}$ & $15 \pm 1.2$ & $23 \pm 2.3$ & $40 \pm 4.2$ & $61 \pm 2.6$ \\
\hline & $1 \times 10^{-8}$ & $4 \pm 1.4$ & $12 \pm 1.9$ & $26 \pm 3.4$ & $47 \pm 1.5$ \\
\hline \multirow[t]{3}{*}{4} & $1 \times 10^{-6}$ & $47 \pm 3.2$ & $56 \pm 3.1$ & $82 \pm 2.8$ & $99 \pm 2.0$ \\
\hline & $1 \times 10^{-7}$ & $28 \pm 1.9$ & $44 \pm 4.4$ & $68 \pm 5.1$ & $90 \pm 4.5$ \\
\hline & $1 \times 10^{-8}$ & $16 \pm 2.6$ & $32 \pm 3.6$ & $53 \pm 3.0$ & $77 \pm 3.7$ \\
\hline \multirow[t]{3}{*}{ 1-c } & $1 \times 10^{-6}$ & $59 \pm 2.1$ & $80 \pm 4.3$ & $100 \pm 2.6$ & $101 \pm 2.5$ \\
\hline & $1 \times 10^{-7}$ & $44 \pm 3.5$ & $65 \pm 5.1$ & $88 \pm 2.3$ & $100 \pm 1.5$ \\
\hline & $1 \times 10^{-8}$ & $33 \pm 3.7$ & $53 \pm 3.3$ & $72 \pm 3.4$ & $90 \pm 4.8$ \\
\hline \multirow[t]{4}{*}{6} & $1 \times 10^{-6}$ & $65 \pm 3.6$ & $84 \pm 3.1$ & $100 \pm 2.6$ & $101 \pm 3.5$ \\
\hline & $1 \times 10^{-7}$ & $53 \pm 2.7$ & $71 \pm 3.9$ & $90 \pm 6.3$ & $101 \pm 3.5$ \\
\hline & $1 \times 10^{-8}$ & $43 \pm 2.8$ & $59 \pm 3.3$ & $79 \pm 2.5$ & $95 \pm 2.5$ \\
\hline & Control & 0 & $2 \pm 0.9$ & $4 \pm 1.4$ & $4 \pm 0.9$ \\
\hline
\end{tabular}

* Time after treatment $(\min )$; \% of motility inhibition activity \pm SE; \% of motility inhibition $=(\mathrm{a}-\mathrm{b}) /(\mathrm{c}-\mathrm{b}) \times 100, \mathrm{a}=$ average number of halted zoospores per microscopic field in treated solution, $\mathrm{b}=$ avearge number of halted zoospores per microscopic field in control solution, $\mathrm{c}=$ average number of halted zoospores per microscopic field from the vortexed $(30 \mathrm{sec})$ zoospore suspension, calculated after $15 \mathrm{~min}$ (33.75). Each test was replicated twice and spores in 4 microscopic fields (randomly) were averaged. 
cardanol-type compounds ( $\mathbf{1} \mathbf{~ m - f}$ and $\mathbf{1} \mathbf{~ m - g}$ ) were practically inactive when tested by particle method using their 1000-ppm solutions $\left(\right.$ ca. $\left.3 \times 10^{-3} \mathrm{M}\right)$, whilst under the same condition, strong activity of $\mathbf{1} \mathbf{~ m}$ and $\mathbf{1} \mathbf{~ m}$-c, and weak activity of $\mathbf{4}$ were clearly detectable (Table I). Since both of the active compounds (1 $\mathbf{m}$ and $\mathbf{1} \mathbf{m}-\mathbf{c}$ ) possessed a $-\mathrm{COOH}$ on the aromatic ring, the presence of a free carboxyl group seemed an important functional group in the anacardic acid relatives for the lytic activity.

To analyze more precise relationships between structure and activity, pure anacardic acid homologues (1-3) and a 2-O-methylanacardic acid (1-c) were prepared and bioassayed. Since a fungicide fluazinam (6) has been reported on its strong lytic activity against Phytophthora zoospores (Andrieu et al., 2001), we successfully employed this synthetic compound as a positive reference for a motility inhibitory and lysis-inducing agent in the present study using Aphanomyces zoospores. Relatively high motility inhibition and lysis-inducing activities against $A$. cochlioides zoospores were expectedly observed in 22:1- $\omega^{7}-2-O$-methylanacar- dic acid (1-c) and 22:1- $\omega^{7}$-anacardic acid (1) as with fluazinam (6) (Tables II and III). 21:1- $\omega^{7}$-Cardol (4), 24:1- $\omega^{9}$-anacardic acid (2, a homologue of 1) were a little less active.

As shown in Tables II and III, the halting and lytic activities were observed in decreasing order of $\mathbf{6}>\mathbf{1}-\mathbf{c}>\mathbf{1}>\mathbf{4}>\mathbf{2}>\mathbf{3}$. Compound $\mathbf{1}$ at $1 \times 10^{-6} \mathrm{M}$ caused $96 \%$ motility inhibition in $20 \mathrm{~min}$ and $67 \%$ lysis of the zoospores within $3 \mathrm{~h}$. Relatively longer time $(\sim 6 \mathrm{~h})$ was required for 4 and 2 to achieve similar lytic activity (data not shown). In contrast, 22:0-anacardic acid (3 with a saturated $\mathbf{1}$ at the aliphatic side chain) exhibited relatively a weak activity and 21:1- $\omega^{7}$-cardanol (5, a decarboxylative product of $\mathbf{1})$ was thoroughly inactive up to $1 \times 10^{-4} \mathrm{M}$ concentration. In respect of structureactivity correlation, active compound possessed common part structures, an aliphatic side chain with one olefinic bond and a carboxyl group on the aromatic ring, which are likely to be necessary to show the activity. In particular, the quantitatively major compound $\mathbf{1}$ in the EtOAc solubles from Ginkgo fruits revealed to be a predominant

Table III. Lytic activity of anacardic acids (1, 2 and $\mathbf{3})$, cardol (4), 2- $O$-methyl-22:1 $\omega^{7}$-anacardic acid (1-c) and a reference compound fluazinam (6) to Aphanomyces cochlioides zoospores.

\begin{tabular}{|c|c|c|c|c|c|}
\hline \multirow[b]{2}{*}{$\begin{array}{l}\text { Tested } \\
\text { compound }\end{array}$} & \multirow[b]{2}{*}{$\begin{array}{c}\text { Concentration } \\
{[\mathrm{M}]}\end{array}$} & \multicolumn{4}{|c|}{ Observed lytic activity* } \\
\hline & & $30 \mathrm{~min}$ & $60 \mathrm{~min}$ & $120 \mathrm{~min}$ & $180 \mathrm{~min}$ \\
\hline \multirow[t]{3}{*}{1} & $1 \times 10^{-7}$ & $10 \pm 2.5$ & $14 \pm 1.2$ & $34 \pm 1.9$ & $55 \pm 2.7$ \\
\hline & $1 \times 10^{-6}$ & $23 \pm 2.7$ & $31 \pm 2.3$ & $47 \pm 2.0$ & $68 \pm 2.7$ \\
\hline & $1 \times 10^{-5}$ & $33 \pm 0.9$ & $43 \pm 2.4$ & $63 \pm 2.2$ & $84 \pm 2.6$ \\
\hline \multirow[t]{2}{*}{2} & $1 \times 10^{-6}$ & $13 \pm 1.3$ & $24 \pm 1.4$ & $34 \pm 4.2$ & $43 \pm 2.8$ \\
\hline & $1 \times 10^{-5}$ & $27 \pm 2.6$ & $39 \pm 2.5$ & $47 \pm 0.9$ & $60 \pm 0.9$ \\
\hline \multirow[t]{2}{*}{3} & $1 \times 10^{-6}$ & $0.5 \pm 2.2$ & $4 \pm 2.0$ & $14 \pm 1.5$ & $28 \pm 2.4$ \\
\hline & $1 \times 10^{-5}$ & $15 \pm 2.0$ & $19 \pm 0.9$ & $30 \pm 0.9$ & $48 \pm 2.0$ \\
\hline \multirow[t]{2}{*}{4} & $1 \times 10^{-6}$ & $20 \pm 3.6$ & $28 \pm 2.2$ & $39 \pm 2.9$ & $54 \pm 2.6$ \\
\hline & $1 \times 10^{-5}$ & $30 \pm 2.6$ & $38 \pm 2.0$ & $50 \pm 2.6$ & $69 \pm 3.0$ \\
\hline \multirow[t]{3}{*}{ 1-c } & $1 \times 10^{-7}$ & $13 \pm 3.6$ & $24 \pm 1.1$ & $39 \pm 3.4$ & $60 \pm 2.6$ \\
\hline & $1 \times 10^{-6}$ & $26 \pm 2.4$ & $36 \pm 2.7$ & $51 \pm 2.6$ & $72 \pm 2.6$ \\
\hline & $1 \times 10^{-5}$ & $39 \pm 0.8$ & $50 \pm 1.5$ & $65 \pm 2.4$ & $87 \pm 1.8$ \\
\hline \multirow[t]{3}{*}{6} & $1 \times 10^{-7}$ & $19 \pm 2.2$ & $29 \pm 2.8$ & $47 \pm 1.6$ & $69 \pm 2.7$ \\
\hline & $1 \times 10^{-6}$ & $29 \pm 2.7$ & $40 \pm 2.1$ & $58 \pm 1.6$ & $79 \pm 1.6$ \\
\hline & $1 \times 10^{-5}$ & $43 \pm 1.9$ & $54 \pm 2.5$ & $71 \pm 1.3$ & $95 \pm 1.3$ \\
\hline
\end{tabular}

* Time after treatment (min): \% of lytic activity \pm SE; \% of lytic activity was calculated, $100-\mathrm{a}, \mathrm{a}=\%$ of unaffected zoospores per microscopic field, $\mathrm{a}=\mathrm{b} \times 100 / \mathrm{c}, \mathrm{b}=$ average number of unaffected zoospores per microscopic field in treated solution, $\mathrm{c}=$ average number of cystospores per microscopic field from the vortexed $(30 \mathrm{sec})$ zoospores suspension calculated after $15 \mathrm{~min}$ (55.25). At $10^{-7} \mathrm{M}$, concentration compounds $\mathbf{2}, \mathbf{3}$ and $\mathbf{4}$ showed very weak lytic activity and not all zoospores were halted after $30 \mathrm{~min}$. Control (without compound) showed no $(0 \%)$ lytic activity. Each test was replicated twice and spores in 4 microscopic fields (randomly) were averaged. 

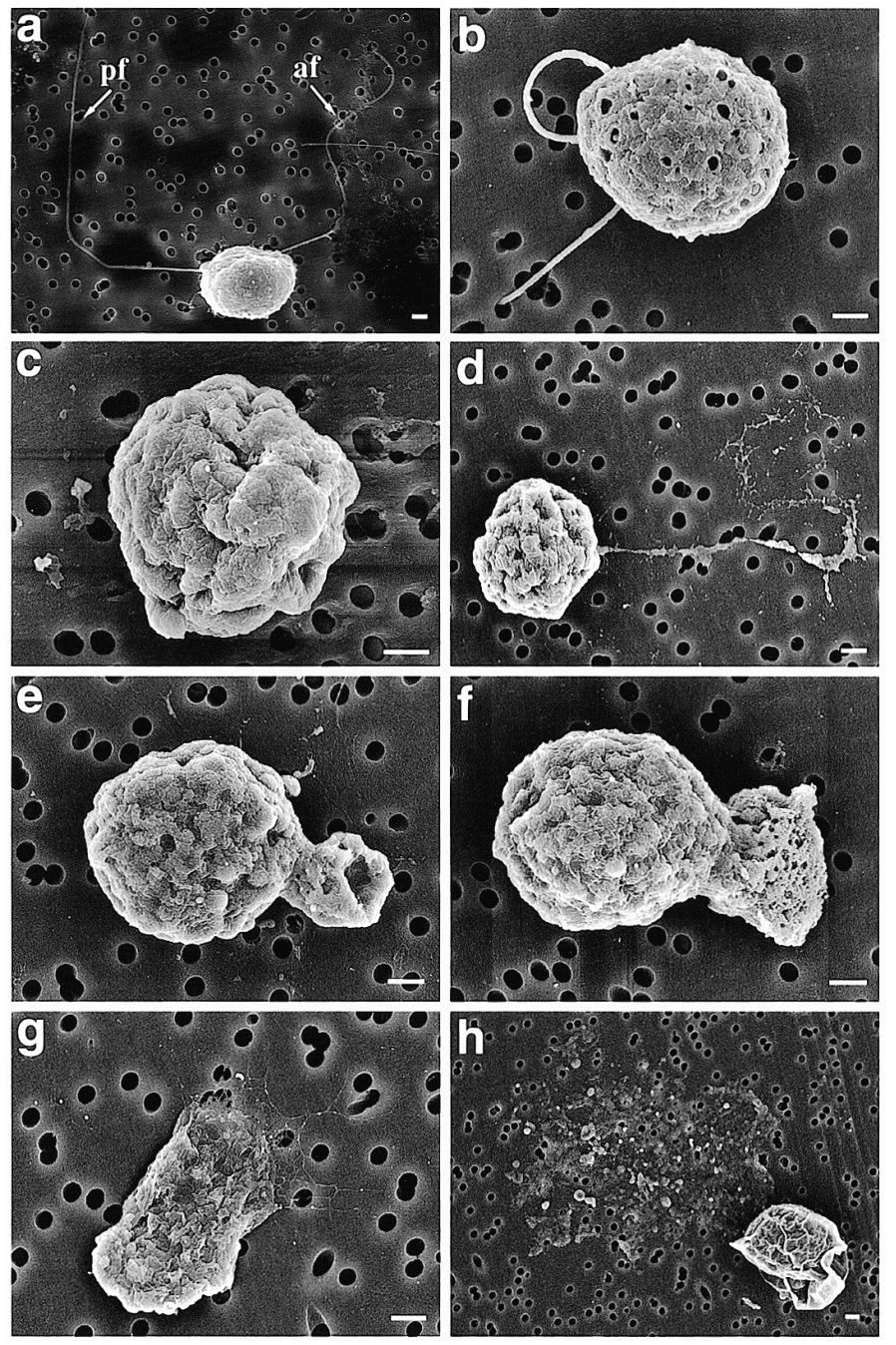

Fig. 2. Zoospore lytic activity of anacardic acid (1) isolated from Ginkgo biloba fruits. a: a bi-flagellated zoospore (af, anterior flagellum; pf, posterior flagellum) and $\mathbf{b}-\mathbf{h}$ : zoospores exposed to anacardic acid (1) at $5 \times$ $10^{-5} \mathrm{M}$ for shown time, b: a nearly roundshaped zoospore (10 $\mathrm{min}), \mathbf{c}-\mathbf{d}$ : dehydrated or squeezed zoospores (20 $\mathrm{min}), \mathbf{e}-\mathbf{g}$ : cellular material coming out through a certain point of spores, $\mathbf{h}$ : traces of a lysed zoospore and a deformed cystospore $(60 \mathrm{~min})$. Scale bars $\mathbf{a}-\mathbf{h}$, $1 \mu \mathrm{m}$. Circular objects in the background are pores (size: $0.6 \mu \mathrm{m}$ ) of SEMpore membrane. factor in quality for the motility inhibitory and zoospore lytic properties of the Ginkgo metabolites.

\section{Morphological changes of zoospores interacting with anacardic acid (1)}

To understand the mode of action, we examined the morphological changes of zoospores interacting with anacardic acid (1) (Fig. 2). Time-course scanning electron microscopic observation revealed that anacardic acid (homogeneous solution method, $5 \times 10^{-5} \mathrm{M}$ ) first damaged fine hairs of flagella and thus halted the zoospores within few min. The affected zoospores immediately turned into a nearly round-shaped spores $(10 \mathrm{~min}$ after treatment, Fig. 2b) leaving or after complete destruction of one or both flagella. The immobile round spores appeared to be dehydrated and squeezed within 20 min after treatment (Fig. 2cd). The membranes of dehydrated spores ruptured at a single point through which the cellular materials gradually released into water (Fig. 2e, f). Finally, all inner materials of the affected cells were came out and dispersed into water within $60 \mathrm{~min}$ (Fig. 2e-g). More than half of the zoospores affected by $1\left(5 \times 10^{-5} \mathrm{M}\right)$ nearly disappeared within $60 \mathrm{~min}$. When some of the zoospores changed into cystospores immediately after the treatment with 1, they were not so easily lysed/burst until $60 \mathrm{~min}$ 
(Fig. 2h), whilst they were also dehydrated and lost their original shape. These deformed cystospores did not proceed to germination or regeneration of zoospores, but gradually lysed few hours later.

\section{Antimicrobial activities of anacardic acids and related compounds}

Antimicrobial activities of anacardic acid (1) and related compounds were also evaluated by paper disc method using two bacteria, Gram-positive $B$. subtilis and Gram-negative E. coli, and a fungus Pythium vexans. Two classes of Ginkgo constituents, anacardic acids ( $\mathbf{1}$ and $\mathbf{2}$ ) and cardanol 4, both possessing significant lytic activity toward $A$. cochlioides zoospores also exhibited growth inhibition of B. subtilis (Table IV). These results indicated the presence of certain links between the lysis-inducing activity to fungal zoospores and antibacterial activity against $B$. subtilis. Not only cardols possessing an unsaturated side chain, but also similarly substituted anacardic acids have been known to be antibiotic against not to Gram-negative, but to Grampositive bacteria (Himejima and Kubo, 1991). Our derivatization experiments revealed a little increase of antibacterial activity against $B$. subtilis in 2-O-methyl derivative (1-c) (activity decreasing order in Table IV: $\mathbf{1 - c}>\mathbf{1 - m}=\mathbf{1}>\mathbf{4}>\mathbf{2}>\mathbf{3}>\mathbf{5}$ ). The sensitivity of a Gram-negative bacterium Escherichia coli to anacardic acids and their derivatives all tested in the present study was expectedly far lower than that of $B$. subtilis. These compounds were all inactive against $P$. vexans at $200 \mu \mathrm{g} /$ disc on a potatodextrose agar medium.

In summary, our results indicate that anacardic acids isolated from $G$. biloba fruits exhibited motility inhibiting and lytic effects on $A$. cochlioides zoospores, and growth inhibitory effects on $B$. subtilis. It became apparent that the partial structures in anacardic acids, for example, the free carboxyl group and unsaturated side chain were responsible for higher zoosporicidal and antibacterial effects, and structural modification, for example 2-Omethylation could improve their activities. Cardol (4) having no carboxyl group, but two hydroxyl groups on the aromatic ring also exhibited noticeable antizoosporic and antibacterial activities, whilst the content of $\mathbf{4}$ in the crude extract of ginkgo fruits was very small $(<0.2 \%)$. However, at present we have no structural information what contributes to such biological activities of 4 . Further understanding of the mode of action of anacardic acids and related compounds against oomycete zoospores should provide important knowledge required for the biorational control of the notorious oomycete phytopathogens.

\section{Acknowledgements}

The authors thank to Mr. K. Watanabe and Dr. E. Fukushi for MS analyses. The authors are

Table IV. Antibacterial activity of anacardic acids and related compounds against Bacillus subtilis.

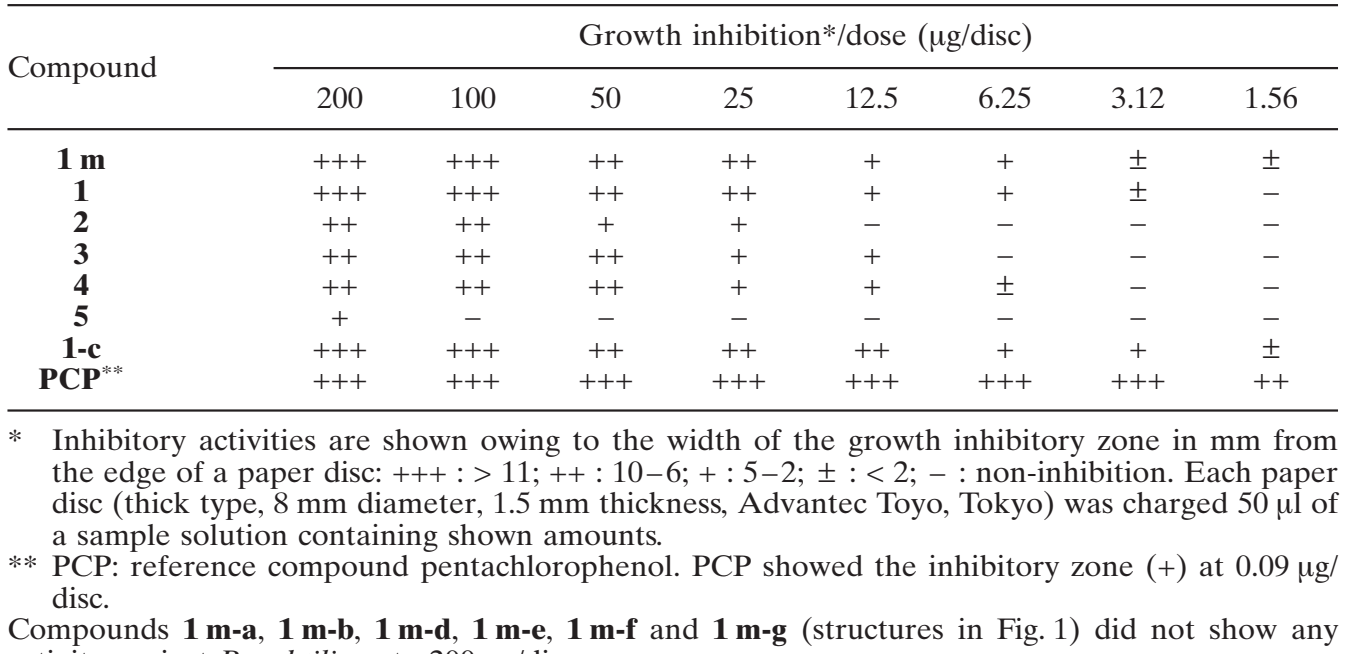

activity against $B$. subtilis upto $200 \mu \mathrm{g} / \mathrm{disc}$. 
also indebted to Dr. K. Yamaji and Dr. H. Ishimoto for their assistance and advise for bioassay and HPLC, respectively and to Mr. T. Ito, Laboratory of Electron Microscopy, Hokkaido University for his technical help in microscopy. The authors are also grateful to the Ministry of Education, Cul- ture, Sports, Science and Technology, Japan for the Scholarship (to P. B.) during her study in Graduate School of Agriculture, Hokkaido University, and for financial support (to S. T.: Grant-in-Aid for Scientific Research, No. 14206013).
Andrieu N., Jaworska G., Genet J. L. and Bompeix G. (2001), Biological mode of action of famoxadone on Plasmopara viticola and Phytophthora infestans. Crop Protection 20, 253-260.

Briskin D. P. (2000), Medicinal plants and phytomedicines. Linking plant biochemistry and physiology to human health. Plant Physiol. 124, 507-514.

Grazzini R., Hesk D., Heininger E., Hildenbrandt G., Reddy C. C., Cox-Foster D., Medford J., Craig R. and Mumma R. O. (1991), Inhibition of lipoxygenase and prostaglandin endoperoxide synthase by anacardic acids. Biochem. Biophys. Res. Commun. 176, 775780.

Himejima M. and Kubo I. (1991), Antibacterial agents from the cashew Anacardium occidentale (Anacardiaceae) nut shell oil. J. Agric. Food Chem. 39, 418-421.

Horio T., Kawabata Y., Takayama T., Tahara S., Kawabata J., Fukushi Y., Nishimura H. and Mizutani J. (1992), A potent attractant of zoospores of Aphanomyces cochlioides isolated from its host, Spinacia oleracea. Experientia 48, 410-414.

Irie J., Murata M. and Homma S. (1996), Glycerol-3phosphate dehydrogenase inhibitors, anacardic acids, from Ginkgo biloba. Biosci. Biotechnol. Biochem. 60, $240-243$.

Islam M. T., Ito, T. and Tahara, S. (2001), Morphological studies on zoospores of Aphanomyces cochlioides and changes during interaction with host materials. J. Gen. Plant Pathol. 67, 255-261.

Itokawa H., Totsuka N., Nakahara K., Takeya K., Lepoittenvin J. P. and Asakawa Y. (1987), Antitumor principles from Ginkgo biloba L. Chem. Pharm. Bull. 35, 3016-3020.

Jaggy H. and Koch E. (1997), Chemistry and biology of alkylphenols from Ginkgo biloba L. Pharmazie 52, $735-738$.
Kubo I., Kinst-Hori I. and Yokokawa Y. (1994), Tyrosinase inhibitors from Anacardium occidentale fruits. J. Nat. Prod. 57, 545-551.

Lepoittevin J. P., Benezra C. and Asakawa Y. (1989), Allergic contact dermatitis to Ginkgo biloba L.: relationship with urushiol. Arch. Dermatol. Res. 281, $227-$ 230.

Shimai T., Islam M. T., Fukushi Y., Hashidoko Y., Yokosawa R. and Tahara S. (2002), Nicotinamide and structurally related compounds show halting activity against zoospores of the phytopathogenic fungus Aphanomyces cochlioides. Z. Naturforsch. 57 c, 323331.

Shobha S. V., Ramadoss C. S. and Ravindranath B. (1994), Inhibition of soybean lipoxygenase-1 by anacardic acids, cardols and cardanols. J. Nat. Prod. 57, $1755-1757$.

Tahara S., Mizutani M., Takayama T. and Ohkawa K. (1999), Plant secondary metabolites regulating behaviour of zoospores of the phytopathogenic fungus Aphanomyces cochlioides. Pesticide Sci. 55, 209-211.

Wang D., Girard T. J., Kasten T. P., LaChance R. M., Miller-Wideman M. A. and Durley R. C. (1998), Inhibitory activity of unsaturated fatty acids and anacardic acids toward soluble tissue factor-factor VIIa complex. J. Nat. Prod. 61, 1352-1355.

Yamaji K., Fukushi Y., Hashidoko Y., Yoshida T. and Tahara S. (1999), Characterization of antifugal metabolites produced by Penicillium species isolated from seeds of Picea glehnii. J. Chem. Ecol. 25, 1643-1653.

Yamagiwa Y., Ohashi K., Sakamoto Y., Hirakawa S. and Kamikawa T. (1987), Syntheses of anacardic acids and ginkgoic acid. Tetrahedron 43, 3387- 3394.

Zarnowska E. D., Zarnowski R. and Kozubek A. (2000), Alkylresorcinols in fruit pulp and leaves of Ginkgo biloba L. Z. Naturforsch. 55c, 881-885. 